\title{
Стратегия «Доброжелательная школа»: проектирование инновационной образовательной среды региона
}

\author{
Зубарева Н.Н. ${ }^{1)}$, Рухленко Н.М.'), Пашкова Г.И.') \\ 1)Департамент здравоохранения и социальной защиты населения Белгородской области, \\ Россия, 308005, Белгородская область, г. Белгород, Свято-Троицкий бульвар, 18 \\ 2) Департамент образования Белгородской области, \\ Россия, 308005, Белгородская область, г. Белгород, пл. Соборная, 4 \\ ${ }^{3)}$ Белгородский государственный национальный исследовательский университет, \\ Россия, 308015, г. Белгород, ул. Победы, 85 \\ E-mail: nzubareva73@mail.ru; NMruhlenko@yandex.ru; pashkova@bsu.ru
}

\begin{abstract}
Аннотация. Обосновано создание доброжелательной образовательной среды, которая определяется как единство системы доброжелательных отношений и образовательной инфраструктуры. При этом проанализированы современные вызовы образованию, порождающие определённые риски, определены миссия, ценности, главные принципы доброжелательной школы, региональные приоритеты, реализация которых позволит обеспечить конкурентоспособность и воспитательную ценность общего и дополнительного образования. Раскрыты основные положения утвержденной постановлением Правительства Белгородской области региональной Стратегии развития образования «Доброжелательная школа» на период 2020-2021 годов, включающей 34 проекта, направленных на формирование доброжелательности как личностной характеристики каждого школьника.
\end{abstract}

Ключевые слова: региональная Стратегия, образовательная среда, национальный проект «Образование».

Для цитирования: Зубарева Н.Н., Рухленко Н.М., Пашкова Г.И. 2020. Стратегия «Доброжелательная школа»: проектирование инновационной образовательной среды региона. Вопросы журналистики, педагогики, языкознания, 39 (2): 216-226. DOI 10.18413/2712-74512020-39-2-216-226

\section{Friendly School strategy: Designing an innovative educational environment in the region}

\author{
Natalia N. Zubareva'), Nikolai M. Rukhlenko(2), Galina I. Pashkova ${ }^{3)}$ \\ ${ }^{1)}$ Department of Health and Social Welfare of the Belgorod Region, \\ 18 St. Trinity Boulevard, Belgorod, 308005, Russia \\ ${ }^{2}$ Department of Education of the Belgorod Region, \\ 4 Sobornaya square, Belgorod, 308005, Russia \\ ${ }^{3)}$ Belgorod National Research University, \\ 85 Pobeda St, Belgorod, 308015, Russia
}

E-mail:nzubareva73@mail.ru; NMruhlenko@yandex.ru; pashkova@bsu.ru

Annotation. The author substantiates the creation of a friendly educational environment, which is defined as the unity of the system of friendly relations and educational infrastructure. At the same time, modern 
challenges to education that generate certain risks are analyzed, the mission, values, main principles of a friendly school, regional priorities are identified, the implementation of which will ensure the competitiveness and educational value of General and additional education. The main provisions of the regional educational development Strategy "Benevolent school" approved by the government of the Belgorod region for the period 2020-2021, which includes 34 projects aimed at forming benevolence as a personal characteristic of each student, are disclosed.

Keywords: regional Strategy, educational environment, national project "Education".

For citation: Zubareva N.N., Rukhlenko N.M., Pashkova G.I. 2020. FriendlySchool Strategy: designing an innovative educational environment in the region. Issues in Journalism, Education, Linguistics, 39 (2): 216-226 (in Russian). DOI 10.18413/2712-7451-2020-39-2-216-226

\section{Введение}

Во все времена вопрос, какой должна быть школа как специальный социальный институт, отличался особой актуальностью. Взгляды на школу постоянно претерпевают изменения. Иначе и быть не может. Так, в отчёте о результатах деятельности Правительства области в 2018 году ${ }^{1}$ Губернатор Белгородской области Евгений Савченко выступил с идеей школы доброжелательной, которая по существу представляет собой продолжение и развитие, только в новых реалиях, реализации федеральных государственных образовательных стандартов, уникального социально-педагогического явления, которым были в регионе на протяжении более четверти века учебно-воспитательные комплексы, представлявшие инновационную и гуманистическую образовательную модель [Исаев, Щербинина, 2014]. Одновременно данная идея созвучна существующему общественному заказу на изменения в отрасли образования и главному современному федеральному приоритету национальному проекту «Образование».

В 2020-2021 годах белгородскому образованию предстоит осуществить огромную, амбициозную и сложную работу по реализации утвержденной постановлением Правительства Белгородской области от 20 января 2020 года № 17-пп² Стратегии развития образования «Доброжелательная школа». Понятие «школа» в данном контексте нами употребляется в широком смысле и подразумевает любую образовательную организацию - общеобразовательную, дошкольную, дополнительного образования, в которых вся жизнедеятельность определяется идеологией доброжелательности.

В последние годы дети все чаще стали проявлять агрессивность, доходящую до жестокости, по отношению не только к сверстникам, но и к взрослым. Обусловлено это, в частности, и тем, что добро и доброта исчезают из повседневной жизни, постепенно переходят на уровень научных и философских понятий. В данной ситуации перед школой стоит одна из важнейших и сложнейших задач: создавать такую образовательную среду, которая вызывала бы у детей стремление к милосердию, состраданию, взаимопомощи и поддержке, приобщала к простому человеческому общению. Сегодня эти извечные нравственные категории являются фундаментом, «который поможет противостоять негативным тенденциям современного общества» ${ }^{3}$.

${ }^{1}$ Отчёт Губернатора Белгородской области Евгения Савченко о результатах деятельности Правительства области в 2018 году. URL: https://belregion.ru/press/news/index.php?ID=29938 (дата обращения: 15.02.2020)

${ }^{2}$ Об утверждении Стратегии развития образования Белгородской области «Доброжелательная школа» на период 2020-2021 годы. 2020. Постановление Правительства Белгородской области от 20 января 2020 года № 17-пп. URL: http://uobr.ru/wp-content/uploads/2020/04/strategiyadsh.pdf (дата обращения: 08.02.2020 г.).

${ }^{3}$ Отчёт Губернатора Белгородской области Евгения Савченко о результатах деятельности Правительства области в 2018 году. URL: https://belregion.ru/press/news/index.php?ID=29938 (дата обращения: 15.02.2020). 
Предлагаемая стратегия доброжелательной школы и ее реализация направлены на то, чтобы поднять добро на новый уровень осознания педагогами, родителями, всеми, кто непосредственно или опосредованно связан с детьми, сделать его социально и личностно практико-ориентированным. Отмечая важность исследуемого феномена, академик Российской академии образования А.А. Лиханов подчеркивает, что «главное - делать людям добро, пусть маленькое, но добро, каждый день, каждый час. Чтобы своим существованием облегчить людям жизнь» [Лиханов, 1985]. Для этого потребуется актуализация ресурсов самых разных направлений: от правовых и финансово-экономических, до кадровых и научно-методических. Именно этим и объясняется факт, что Стратегия «Доброжелательная школа» включает 9 разнонаправленных портфелей проектов, реализация которых, в конечном итоге, направлена на изменение образовательной среды [Рухленко, 2020].

Первым этапом разработки стратегии доброжелательной школы являлся этап осмысления происходящих в сфере образования процессов, основное содержание которого составил проблемный анализ процессов, происходящих в сфере образования в условиях региона, и изучение позитивного зарубежного педагогического опыта [Martorel et al., 1990].

Второй этап - это этап разработки концепции доброжелательной школы и моделей доброжелательного детского сада, доброжелательной школы и доброжелательного дополнительного образования с учетом результатов проблемного анализа состояния образовательной среды региона.

На третьем этапе состоялись стратегические проектные сессии с привлечением общественности и экспертного сообщества, в том числе детского, на которых обсуждались концепция доброжелательной школы, Кодекс доброжелательности, чек-листы по определению доброжелательности учреждения (по двум модулям: «Образовательная инфраструктура» и «Содержание образования»); проводились конкурсы сочинений, слоганов и эмблем. В обсуждении приняли участие более двух тысяч респондентов, что свидетельствует, с одной стороны, об актуальности проблемы, с другой - о заинтересованности общественности в изменениях в сфере образования.

Цель Стратегии заключается в определении региональных приоритетов в построении на территории области доброжелательной образовательной среды, способной обеспечить воспитательную ценность общего и дополнительного образования. В процессе анализа определена миссия доброжелательной школы: предоставить всем участникам образовательного пространства максимальные возможности с удовольствием и пользой для собственного будущего накапливать и реализовывать личностный потенциал. Психологически безопасную, наполненную позитивом образовательную среду в школе могут создавать креативные, стремящиеся к постоянному личностно-профессиональному саморазвитию, инициативные и ответственные за свои действия педагоги, дома - любящие своих детей родители. При этом образовательную среду мы определяем как единство системы доброжелательных отношений в системах: «учитель - ученик», «ученик ученик», «учитель - родитель», «учитель - руководитель», «родитель - руководитель» [Менг, Лабунская, 2001].

\section{Проектирование образовательного пространства региона}

На наш взгляд, система доброжелательных отношений (нематериальная составляющая образовательной среды) складывается из отношений в организации (психологический климат, воспитательное и коммуникативное пространство, система управления), которые закреплены соответствующей нормативно-правовой базой, включая образовательные программы, информационной среды (содержание информационного образовательного пространства в сети Интернет, а также специализированные образовательные платфор- 
мы, например, для дистанционного образования), социокультурной среды (специфические характеристики образовательной организации, сформированные намеренно: традиции, уклад жизни).

Охарактеризуем образовательную среду Белгородской области с позиции «Как есть?». Хотя объективно это сделать очень непросто, так как не существует единых подходов и критериев оценки влияния среды на результаты образовательного процесса. За основу нами были взяты показатели качества авторитетных российских исследований, национальных и международных мониторингов, которые в разное время проводились в России, в том числе и на территории Белгородской области [Менг, Лабунская, 2001; Тарасов, 2014; и др.].

На основании экспертных оценок, сделанных управленцами разного уровня, педагогами, родителями мы представили ситуацию «Как есть?» в виде социального заказа для города и для села. В отдельную группу нами были выделены общие приоритеты для городских и сельских школ: 1) квалификация педагогических кадров, компетентная управленческая команда, профессиональный рост учителя; 2) современное информационное программное обеспечение и передовые педагогические технологии; 3) система воспитания и внеклассной работы, наличие внутришкольной культуры и традиций; 4) доброжелательные отношения между учителями, учениками и родителями, их поддержка; 5) «школа полного дня», в которой совмещаются программы общеобразовательной школы и дополнительного образования; 6) наличие программы развития школы, центральное место в которой занимает программа воспитания.

В рамках реализации национального проекта «Образование» поставлена задача добиться более высоких результатов в международных исследованиях, таких как PISA, TIMSS, PIRLS. Школа как основная и самая продолжительная ступень этого образования становится ключевым моментом обеспечения её решения и повышения качества, которое мы понимаем как соответствие уровня образования потребностям, интересам личности, общества, государства. К сильным сторонам российского общего образования относятся высокий уровень академических знаний школьников, способность решать типовые учебные задачи на основе полученных знаний; слабое место - неумение применять полученные знания на практике для решения проблемных ситуаций.

Кроме того, не следует забывать и о современных вызовах образованию, порождающих определённые риски. Без их понимания и осмысления создание доброжелательной школы затруднено. К основным мы относим нестабильность института семьи и духовный кризис современного общества. В механизмах семейного воспитания происходят глубинные изменения: во многих семьях оба родителя нацелены на карьеру; растёт доля однодетных семей; даже в полных семьях наблюдается устранение отцов от вопросов воспитания; все явственнее проявляются признаки жестокости, равнодушия, потребительства.

Появление новых каналов и источников информации, резкое возрастание возможностей доступа к любым информационным сегментам современного мира - следующий глобальный вызов, связанный с утратой школой монополии на обучение, воспитание и социализацию. В странах-лидерах в образовании данной утрате уже противопоставлены активные действия по превращению школ в координаторов образования и социализации, выходу за пределы формального образования в так называемую «сеть» по использованию возможностей других социальных институтов. Старшая школа перестала по-настоящему образовывать. Пошатнулась педагогическая, дидактическая и методическая культура урока. Неустойчивые внутренние принципы и ориентиры зачастую вступают в противоречие с моральными нормами общества. Мы всё еще далеки от истинного понимания, что такое здоровье, и воспринимаем его как отсутствие болезней и физических недостатков. Тогда как здоровье - это состояние полного физического, психического и социального благопо- 
лучия. В школе достаточно распространены такие нежелательные явления, как переутомление и перегрузка. Следует признать, что современные условия организации учебной деятельности в целом более соответствуют особенностям учащихся с сильной нервной системой, тогда как необходимо сделать все возможное для того, чтобы дети со слабой нервной системой также чувствовали себя в классном коллективе комфортно.

На своих переговорных площадках мы много размышляли о ценностях доброжелательной школы [Латышина, 2005]. В качестве основных ценностей определены жизнь, патриотизм, гражданственность, семья, православие, знание, здоровье, добро. Главной ценностью является жизнь, потому что этовеликое чудо и величайшее благо, дарованное человеку. В доброжелательной школе учат понимать, что важно любить свою жизнь и в то же время уважать и ценить жизни других людей, что жизнь нужно всячески беречь и наполнять её лишь светлым и созидательным. В современных условиях патриотизм и гражданственность имеют особое значение, потому что без них нельзя возродить сильное государство, создать гражданское сообщество, привить людям понимание своего долга, своих прав, уважения к законам, к своей Конституции. В России православие всегда содействовало становлению человека. Именно на православных идеалах формировались традиции русской жизни и лучшие качества человека и гражданина. Необходимо помнить, какую позитивную роль сыграл предмет «Православная культура» в лихие для нашего Отечества годы, когда Белгородчина смело внедрила его в учебные планы с 1 по 11 класс. Результат: более воспитанные дети, более добрые отношения между учениками. Определяя в качестве ценности знание, участники проектных сессий были единодушны в том, что оно, с одной стороны, выступает в качестве основания для диалога культур, понимания другого и мира в целом, а с другой - знание - это ценность, если оно неотделимо от добродетели. Существенный рост высокобалльников показал, что наша молодёжь всё более воспринимает знание как величайший капитал для самореализации. Здоровье является путём к сбалансированному, гармоничному существованию души и тела. Добро наполняет жизнь человека смыслом, оно становится самоценным, а не служит средством для достижения других целей [Сухомлинский, 1982].

Определены главные принципы доброжелательной школы: не оставлять без внимания ни одного ребенка; успех всех и успех каждого; активное участие родителей в жизни школы; школа - территория безопасности детей; школа для и ради детей; обеспечение высокого уровня образовательной деятельности; объективность оценки; событийность; воспитание через коллектив; благо детей прежде всего; свобода, активность и сопричастность; учёт интересов детей и родителей [Roland, 1975].

Остановимся подробнее на способах решения обозначенных проблем через реализацию отдельных портфелей проектов Стратегии. Первый из них управленческий. Он направлен на совершенствование структуры управления сферой образования, прежде всего на муниципальном уровне. Для этого сделано следующее: 1) сформированы четыре группы муниципалитетов, исходя из количества образовательных организаций и контингента обучающихся; 2) разработаны и направлены в муниципальные образования примерные структуры управлений для каждого кластера с указанием количества штатных единиц, достаточных для выполнения тех или иных функций и полномочий в сфере образования; 3) разработаны примерное положение о муниципальном органе управления образованием, должностные регламенты сотрудников; 4) проведена реорганизация структур муниципальных органов управления образованием, 5) заключены новые соглашения о реализации единой образовательной политики в регионе на уровне Губернатора области и глав администраций муниципальных районов и городских округов; 6) создана сеть государственных школ - ресурсных центров, в том числе опорных школ Российской академии 
наук, которые станут методическими и инновационными площадками по актуальной проблематике в сфере обучения и воспитания.

«Лидеры образования» - это следующий портфель проектов, один из которых связан с репетиторством. Понимая, что рынок таких услуг будет существовать всегда, тем не менее считаем, что базовые знания должны даваться в школе, и домашняя работа должна выполняться там же. Ниша репетиторских услуг - это, прежде всего, «надбазовые» потребности детей и их родителей, например, ЕГЭ на 100 баллов, или подготовка к вузовской олимпиаде, или занятия с логопедом, дефектологом, психологом. Предлагаются две модели реализации доступных и качественных репетиторских услуг: содействие регистрации индивидуальных предпринимателей и объединение их в соответствующее сообщество (ассоциацию); стимулирование СОНКО на оказание репетиторских услуг через реализацию программ дополнительного образования при условии получения ими лицензии.

Следующий портфель - содержательный, связанный с процессами обучения и воспитания. Социальный заказ в современной ситуации - это школа полного дня, когда в рамках одного учреждения ребёнок находится под присмотром, обеспечен питанием, приготовил домашнее задание, посетил секции и кружки и находится в безопасности. Школа полного дня работает с утра до вечера. Здесь у каждого ребёнка свой режим проживания, интегрированы общее и дополнительное образование. Все письменные домашние задания выполняются в школе, для этого в режиме дня выделяется специальное время - самоподготовка.

Школа полного дня предполагает результативность двух часов неаудиторной нагрузки, предусмотренных для работы учителя со слабоуспевающими (один час) и одарёнными (один час) школьниками. Одарённые школьники готовятся к олимпиадам, интеллектуальным конкурсам, углубляются в учебный материал. В основе формирования групп детей, которые по тем или иным причинам не раскрыли свой образовательный потенциал, - трудности, выявленные в освоении программы. Эти группы немногочисленные (до 8 человек) и временные. Пробел устранён - нет необходимости посещать дальнейшие занятия. Это место займёт кто-то другой.

Широкое развитие в школе полного дня получат площадки для консультирования по предметам, по которым есть письменные домашние задания, на эти цели из внеурочной деятельности выделяется два часа. Это разовые занятия. На консультацию приходят те, у кого возник какой-то вопрос, в том числе при подготовке к контрольной работе. На «скорую помощь» ученик может рассчитывать по любому предмету. Получат развитие консультационные площадки для обучающихся 9-11 классов в целях подготовки к экзаменам. График консультаций определяется школой самостоятельно исходя из запросов детей и доступен в электронном виде.

Идее школы полного дня в наибольшей мере соответствуют образовательные комплексы, так как позволяют эффективно использовать возможности сети, развести обучение по уровням, разумно использовать оборудование. В ходе реализации портфеля будет внедрён иной воспитательный стандарт.Чтобы получить в качестве личностной характеристики каждого ребёнка доброжелательность, потребуется единое региональное доброжелательное воспитательное пространство, параметры которого заданы приоритетными ценностями и Кодексом доброжелательности, представляющим уровневый свод правил, и уровневыми портретами выпускника белгородской школы в соответствии с ценностями доброжелательной школы.Поддерживая инициативу Министерства просвещения и Министерства культуры о реализации проекта «Культурный норматив школьника», мы предлагаем пойти дальше - рассматривать понятие «культура» в самом широком смысле, включая и художественную, и духовную, и физическую культуру, и разработать культурный 
норматив для юных белгородцев начиная с самого раннего возраста, не ограничиваться «пассивным» восприятием художественных ценностей, а вовлекать ребят в активное освоение и присвоение культурных единиц. Сообразно своему возрасту дети и подростки будут осваивать музыкальные и художественные произведения, учиться танцевать, изучать песенный репертуар, этикет и правила здорового питания, осваивать курсы «Нравственные основы семейной жизни», «Православная культура».

Предложен новый подход к организации дополнительного образования в условиях школы полного дня [Зубарева и др., 2015]:

- 1-4 классы - учащимся предлагаются различные виды деятельности, освоение программ, большинство из которых рассчитано на срок не более одного года. Выбирать и менять программы учащиеся могут, используя специальный навигатор. Важно, чтобы каждый учащийся смог попробовать себя в различных видах деятельности;

- 5-8 классы - учащимся этих классов предлагается участвовать в социально значимых проектных практиках;

- 9-11 классы - учащиеся выпускных классов могут участвовать в научных обществах, взаимодействовать в разных формах с высшими и средними профессиональными учебными заведениями, решая главные на этом возрастном этапе задачи профессионального самоопределения.

Один из проектов данного портфеля посвящён дошкольному образованию. Родительский запрос сегодня явно устремлён на ожидание высокого уровня интеллектуальной подготовленности детей к школе. Но при этом доброжелательный детский сад должен оставаться играющим и обогащающим, а не учебно-дисциплинарным. Ведущим видом деятельности должна быть игра, позволяющая формировать в единстве и взаимодействии все стороны личности ребенка. Кроме того, в качестве задачи определяем возрождение системы наставничества и шефства среди детей во всех белгородских школах, которая с конца 80-х годов прошлого века оказалась забытой.

Портфель проектов «Развитие психолого-педагогической службы региона» направлен на профилактику профессионального выгорания педагогов, создание регионального родительского клуба «Ответственное родительство», обеспечение психологической безопасности каждого ребёнка, разработку единого порядка выявления детей из групп социального риска и их сопровождение, формирование эффективного механизма информационного взаимодействия при кризисных ситуациях [Jun, 1989]. Ocобое место занимает разработка и внедрение единой модели психолого-педагогического сопровождения системы доброжелательных отношений. Базовыми задачами психологопедагогической службы являются оказание психолого-педагогической помощи субъектам образовательного процесса в установлении доброжелательных взаимоотношений в системах «ученик - учитель» и «ученик - ученик»; оказание психолого-педагогической, медицинской и социальной помощи детям, испытывающим трудности в освоении общеобразовательных программ, интеллектуальном и личностном развитии, социальной адаптации [Grissemann, 1989]. Дополнительно к действующим одному региональному и двум муниципальным центрам психолого-педагогической, медицинской и социальной помощи будут созданы еще одиннадцать [Баева, 2002].

Бережливое управление - это тема очередного портфеля проектов. Понятия «доброжелательная школа» и «бережливая школа» неразделимы, это изменение культуры, идеологии, сознания людей. Процессы визуализации, внешней и внутренней логистики, разделения потоков обучающихся, создания комфортных зон ожидания, электронное расписание - это то, что будет оказывать долгосрочный эффект на весь образ жизни любой образовательной организации. 
Региональная стратегия «Доброжелательная школа» предполагает изменение архитектуры методического пространства региона. Этому посвящён ещё один портфель проектов. Отдельными штрихами обозначим его суть. Основная задача методических служб содействие в развитии творческого потенциала педагогических работников, что, в свою очередь, предъявляет соответствующие требования к методистам. Предложенная модель методической службы региона охватит от 70 до 170 образовательных организаций с численностью от 1500 до 4500 педагогов.

Достижению успеха в реализации Стратегии будет способствовать авторитетная дискуссионная и коммуникационная площадка в виде областной педагогической газеты. Практика Старого Оскола, где выпускается образовательная газета, показывает её востребованность. Совместно с Издательским Домом «Мир Белогорья» разработан медиапроект по созданию газеты «Доброжелательная школа Белогорья» в печатном и электронном варианте, первый выпуск которой состоялся уже в августе прошлого года. Данное издание станет продуктивным транслятором идеи доброжелательности на широкую читательскую аудиторию.

\section{Образовательная инфраструктура}

Успешное функционирование образовательной организации во многом зависит от качества образовательной инфраструктуры, которое, в свою очередь, зависит от эффективности управленческих решений [Исаев, 1997]. На решение этой задачи направлен портфель проектов «Развитие инфраструктуры сферы образования». Для анализа ситуации «Как есть?» использовалась методика Высшей школы экономики для расчета индекса образовательной инфраструктуры, рекомендованная Министерством просвещения Российской Федерации [Агранович и др., 2019]. Качество инфраструктуры оценивалось на четырёх уровнях общего образования: дошкольное, начальное общее, основное общее, среднее общее) и в дополнительном образовании; для каждого уровня и вида образования были выделены четыре группы показателей: кадровое обеспечение (укомплектованность кадрами, их квалификационные характеристики, уровень оплаты труда); материальнотехническое обеспечение (состояние зданий и территорий образовательных организаций (в том числе ландшафтное благоустройство), наличие современного оборудования, специализированных помещений); создание условий для осуществления инклюзии (наличие условий для получения качественного и доступного образования детьми с ограниченными возможностями здоровья и детьми-инвалидами); информационно-методическое обеспечение (информатизация для детей и взрослых (в том числе условия для телеобразования), библиотечные фонды и возможность их использования в образовательном пространстве). Оценивалась также и региональная образовательная сеть, характеризующая доступность образовательных услуг для детей вне зависимости от места их проживания.

Были выявлены как сильные, так и слабые стороны современной образовательной инфраструктуры, которые мы рассматриваем в качестве точек роста: 1) недостаточные условия для инклюзии в школах и учреждениях дополнительного образования в отличие от детских садов; 2) малое количество в школах молодых учителей, педагогов-психологов; 3) наличие зданий, в которых капительный ремонт не проводился более 25 лет; 4) недостаточная оснащенность учебным оборудованием и мебелью; 5) отсутствие лицензии на медицинскую деятельность в 15 \% организаций, в которых созданы медицинские кабинеты и др.

Таким образом, в целом материальная база региональной отрасли образования находится в удовлетворительном состоянии; при этом есть проблемные поля, которые позволяют определить приоритеты в процессе построения образовательной инфраструктуры доброжелательной школы. 
Отсутствие в образовательных организациях зонирования образовательного пространства для активного и пассивного отдыха школьников разных возрастов, педагогов, руководителей, родителей вызвало необходимость разработки проекта «Формирование доброжелательного образовательного пространства», в рамках которого планируется строительство и капитальный ремонт образовательных организаций; создание рекреационных пространств внутри помещений; ландшафтное благоустройство прилегающей территории с формированием зон образовательной, двигательной активности; создание доступной среды для детей с ОВ3; разработка модели улучшения оформления свободного пространства, организации зон психологического комфорта, так называемых «коворкингзон» (зон общения).

При этом не сама по себе материальная база, а создание образовательной среды как системы доброжелательных отношений в условиях соответствующей образовательной инфраструктуры является необходимым и достаточным условием качественного образования. Можно перенасытить учреждение оборудованием и иными материальными благами, но без внутреннего содержания и атмосферы желаемого результата не достичь.

\section{Заключение}

Таким образом, эффективная реализация портфелей проектов Стратегии доброжелательной школы будет, несомненно, способствовать созданию доброжелательной, комфортной, благоприятной среды для всех участников образовательных отношений; все проекты в конечном итоге сработают на повышение качества образования в регионе.

Доброжелательность - это как раз тот фундамент, который поможет противостоять негативным тенденциям современного общества, существующим сложным социальнопсихологическим проблемам.

Главным результатом реализации модели доброжелательной школы является новый ученик, новый учитель и новый родитель. Разработанные требования к данному результату основаны на образах выпускников и педагогов, зафиксированных в федеральных государственных образовательных стандартах, и дополнены в соответствии с концепцией доброжелательной школы.

Ученик доброжелательной школы должен обладать следующими характеристиками и качествами: социальной совестью; сопереживанием; уважением человеческого достоинства; развитым эмоциональным интеллектом; критическим мышлением; готовностью к поддержке; умением сотрудничать.

Качества и характеристики учителя и руководителя доброжелательной школы: безоценочное общение по отношению к личности; эмоциональный интеллект; уважение человеческого достоинства; владение навыками создания ситуации успеха; готовность к поддержке; умение сотрудничать; учёт психофизиологических особенностей учащихся. Доброжелательный родитель - это родитель с безоценочным отношением к собственному ребенку, обладающий эмоциональным интеллектом; уважающий человеческое достоинство; владеющий техниками поддержки, общения; социально активен; готов к поддержке; умеет сотрудничать.

\section{Список источников}

1. Лиханов А.А. 1985. Мой генерал. М., Детская литература, 175 с.

2. Сухомлинский В.А. 1982. Разговор с молодым директором школы. М., Просвещение, 206 с.

\section{Список литературы}

1. Агранович М.Л., Ермачкова Ю.В., Селиверстова И.В. 2019. Российское образование в контексте международных индикаторов. М., ФИРО РАНХиГС, 96 с.

2. Баева И.А. 2002. Психологическая безопасность в образовании. СПб., СОЮЗ, 271 с. 
3. Зубарева Н.Н., Светенко Т.В., Востокова С.Н. 2015. Создание муниципальных социально ориентированных систем организации внеурочной занятости школьников. Старый Оскол, Кириллица, $132 \mathrm{c.}$

4. Исаев И.Ф. 1997. Школа как педагогическая система: основы управления. Белгород, Издательство Белгородского государственного университета, 145 с.

5. Исаев И.Ф., Щербинина В.М. 2014. Сельские учебно-воспитательные комплексы Белгородчины: историко-педагогический аспект (1974-1991). Белгород, ГиК, 252 с.

6. Латышина Д.И. 2005. История педагогики (История образования и педагогической мысли). М., Гардарики, 603 с.

7. Менг Т.В., Лабунская Н.А. 2001. Образовательная среда: подходы к раскрытию понятия. В кн.: Образовательная среда школы: проблемы и перспективы развития. СПб, Союз: 3-23.

8. Рухленко Н.М. 2020. От аналитической работы - к практической деятельности (из опыта разработки региональной Стратегии развития образования «Доброжелательная школа»). В кн.: Доброжелательное образовательное пространство: инновационные практики школы и вуза. Материалы Всероссийской научно-практической конференции. Белгород, Издательский дом НИУ «БелГУ»: 11-19.

9. Тарасов С.В. 2014. Образовательная среда: понятие, структура, типология. Вестник Ленинградского государственного университета им. А.С. Пушкина, 3(1): 133-138.

10. Grissemann H. 1989. Lernbehinderung heute: psychologisch-anthropologische Grundlagen einer innovativen Lernbehindertenpдdagogik. A. Rett. Bern; Stuttgart; Toronto, Verlag Hans Huber, 214 p.

11. Jun Gerda. 1989. Kinder, ie anders sind: ein Elternreport. Berlin, VEB Verlag Volk und Gesundheit, $186 \mathrm{p}$.

12. Martorel G., Papalia D., Feldman R. 1990. Child's World: infancy through Adolescence. palia, aut. New York; St. Louis; San Francisco, McGraw-Hill Humanities/Social Sciences/Languages, 625 p.

13. Roland D., Hennig W. 1975. Der Schüler von zehn bis sechzehn: Zur Erziehung in der Familie. Berlin, Volk und Wissen Volkseigener Verlag.

\section{References}

1. Agranovich M.L., Ermachkova Iu.V., Seliverstova I.V. 2019. Rossiiskoe obrazovanie v kontekste mezhdunarodnykh indikatorov [Russian education in the context of international indicators]. M., Publ. FIRO RANKHiGS, 96 p.

2. Baeva I.A. 2002. Psikhologicheskaia bezopasnost v obrazovanii [Psychological security in education]. SPb, Publ. SOIUZ, 271 p.

3. ZubarevaN.N., SvetenkoT.V., VostokovaS.N. 2015. Sozdanie munitsipalnykh sotsialno orientirovannykh sistem organizatsii vneurochnoi zaniatosti shkolnikov [Creation of municipal socially oriented systems for organizing extracurricular employment of schoolchildren]. Staryi Oskol, Publ. Kirillitsa, $132 \mathrm{p}$.

4. Isaev I.F. 1997. Shkola kak pedagogicheskaia sistema: osnovy upravleniia [School as a pedagogical system: fundamentals of management]. Belgorod, Publ. Belgorodskogo gosudarstvennogo universiteta, $145 \mathrm{p}$.

5. Isaev I.F., Shcherbinina V.M. 2014. Selskie uchebno-vospitatelnye kompleksy Belgorodchiny: istoriko-pedagogicheskii aspekt (1974-1991) [Rural educational complexes of Belgorod region: historical and pedagogical aspect (1974-1991)]. Belgorod, Publ. GiK, 252 p.

6. Latyshina D.I. 2005. Istoriia pedagogiki (Istoriia obrazovaniia i pedagogicheskoi mysli) [History of pedagogy (History of education and pedagogical thought)]. M., Publ. Gardariki, 603 p.

7. Meng T.V., Labunskaia N.A. 2001. Obrazovatelnaia sreda: podkhody k raskrytiiu poniatiia [Educational environment: approaches to the disclosure of the concept]. In: Obrazovatelnaia sreda shkoly: problemy i perspektivy razvitiia [Образовательная среда школы: проблемы и перспективы развития]. $\mathrm{SPb}$, Publ. Soiuz:3-23.

8. Rukhlenko N.M. 2020. Ot analiticheskoi raboty - k prakticheskoi deiatelnosti (iz opyta razrabotki regionalnoi Strategii razvitiia obrazovaniia «Dobrozhelatelnaia shkola») [From analytical work to practical activities (from the experience of developing a regional Strategy for the development of education "Benevolent school")]. In: Dobrozhelatelnoe obrazovatelnoe prostranstvo: innovatsionnye praktiki shkoly i vuza. Materialy Vserossiiskoi nauchno-prakticheskoi konferentsii [Friendly educational space: 
innovative practices of schools and universities. Materials of the all-Russian scientific and practical conference]. Belgorod, ID NIU «BelGU»: 11-19.

9. Tarasov S.V. 2014. Obrazovatel'naya sreda: ponyatie, struktura, tipologiya [Educational environment: concept, structure, typology]. Vestnik Leningradskogo gosudarstvennogo universiteta im. A.S. Pushkina - Bulletin of the Leningrad state University named after A. S. Pushkin, 3(1): 133-138.

10. Grissemann H. 1989. Lernbehinderung heute: psychologisch-anthropologische Grundlagen einer innovativen Lernbehindertenpädagogik. A. Rett. Bern; Stuttgart; Toronto, Verlag Hans Huber, 214 p.

11. Jun Gerda. 1989. Kinder, ie anders sind: ein Elternreport. Berlin, VEB Verlag Volk und Gesundheit, $186 \mathrm{p}$.

12. Martorel G., Papalia D., Feldman R. 1990. Child's World: infancy through Adolescence. palia, aut. New York; St. Louis; San Francisco, McGraw-Hill Humanities/Social Sciences/Languages, 625 p.

13. Roland D., Hennig W. 1975. Der Schüler von zehn bis sechzehn: Zur Erziehung in der Familie. Berlin, Volk und Wissen Volkseigener Verlag.

\section{ИНФОРМАЦИЯ ОБ АВТОРАХ}

\begin{abstract}
Зубарева Наталия Николаевна, кандидат педагогических наук, доцент, заместитель Губернатора Белгородской области - начальник департамента здравоохранения и социальной защиты населения Белгородской области, г. Белгород, Россия
\end{abstract}

Рухленко Николай Михайлович, первый заместитель начальника департамента образования - начальник управления образовательной политики департамента образования Белгородской области, г. Белгород, Россия

Пашкова Галина Ивановна, кандидат педагогических наук, доцент, доцент кафедры русского языка и литературы Белгородского национального исследовательского университета, г. Белгород, Россия

\section{INFORMATION ABOUT THE AUTHORS}

Natalia N. Zubareva, Candidate of Pedagogical Sciences, Associate Professor, Deputy Governor of the Belgorod Region - Head of the Department of Health and Social Protection of the Population of the Belgorod Region, Belgorod, Russia

Nikolai M. Rukhlenko, First Deputy Head of the Department of Education - Headofthe Department of Educational Policy of the Department of Education of the Belgorod Region, Belgorod, Russia

Galina I. Pashkova, Candidate of Pedagogical Sciences, Associate Professor, Associate Professor of the Department of Russian Language and Literature, Belgorod National Research University, Belgorod, Russia 